\title{
Editorial
}

\section{Mathematical Engineering and Control with Applications}

\author{
Mamdouh M. El Kady, ${ }^{1,2}$ Martin J. Bohner, ${ }^{3}$ J. Liang, ${ }^{4}$ and Mouffak Benchohra ${ }^{5}$ \\ ${ }^{1}$ Helwan University, P.O. Box 11795, Cairo, Egypt \\ ${ }^{2}$ Canadian International College (CIC), Zayed Branch, 6th Oct., Giza, Egypt \\ ${ }^{3}$ Department of Mathematics and Statistics, Missouri University of Science and Technology, 106 Rolla Building, Rolla, \\ MO 65409-0020, USA \\ ${ }^{4}$ Department of Mathematics, Shanghai Jiao Tong University, Shanghai 200240, China \\ ${ }^{5}$ Laboratoire de Mathématiques, Université de Sidi Bel Abbes, BP 89, 22000 Sidi Bel Abbes, Algeria
}

Correspondence should be addressed to Mamdouh M. El Kady; mam_el_kady@yahoo.com

Received 4 August 2013; Accepted 4 August 2013

Copyright (C) 2013 Mamdouh M. El Kady et al. This is an open access article distributed under the Creative Commons Attribution License, which permits unrestricted use, distribution, and reproduction in any medium, provided the original work is properly cited.

This special issue publishes carefully selected papers covering applied mathematics, optimal techniques, and their applications to science and engineering. Typical theoretical areas covered in this issue include linear, nonlinear, mathematical, and dynamic programming. Among the areas of application covered are mathematical physics, aerospace, chemical, civil, electrical, and mechanical engineering.

This issue publishes only contributed papers as well as gathering together the revised versions of the best selected papers presented to this issue.

The quality of the 9 papers printed here is evident just by reading them, but some figures can better help the reader to understand how strict the selection procedure has been reviewed by at least three different reviewers, and the total number of papers submitted to this issue was 60 . Together, these papers represent an exceptional version of the mathematical engineering and optimal control applications and provide a unique high quality collection of innovative ideas.

We hope you enjoy the results of the hard work of the reviewers and the authors.

\section{Acknowledgment}

We would like to heartily thank all the reviewers whose comments have substantially contributed to this special issue.

Mamdouh M. El Kady

Martin J. Bohner

J. Liang

Mouffak Benchohra 


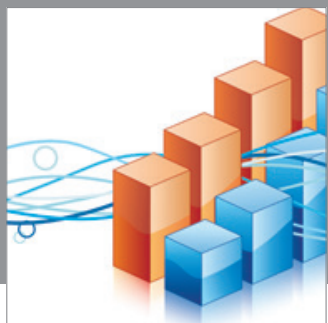

Advances in

Operations Research

mansans

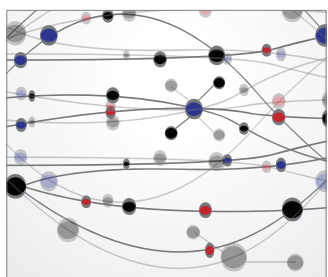

The Scientific World Journal
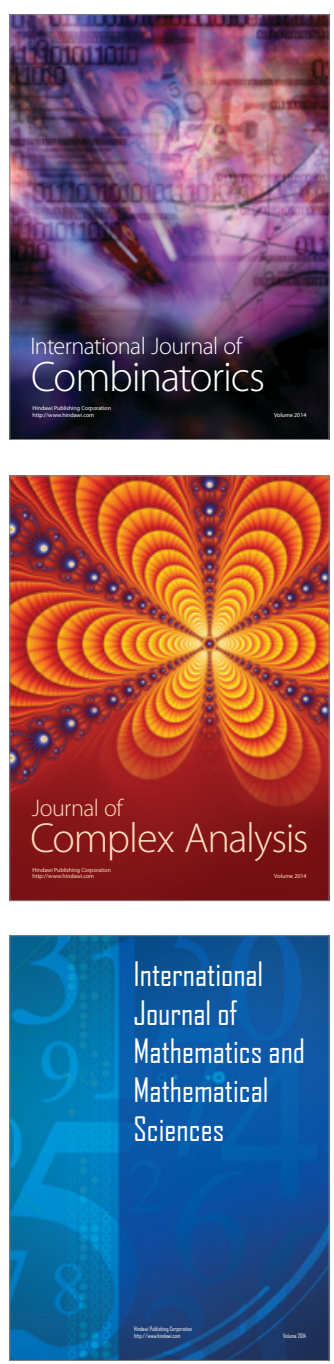
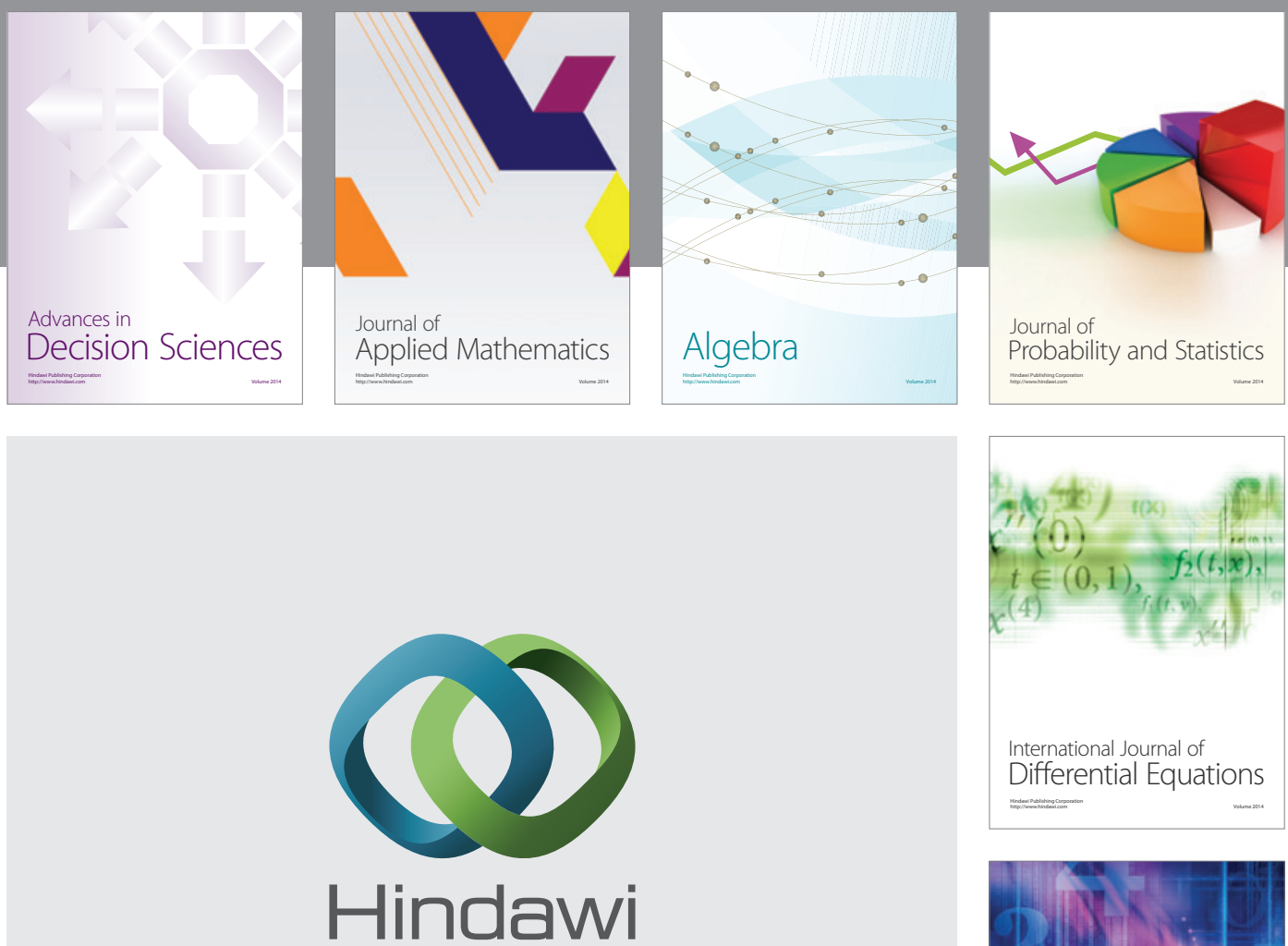

Submit your manuscripts at http://www.hindawi.com
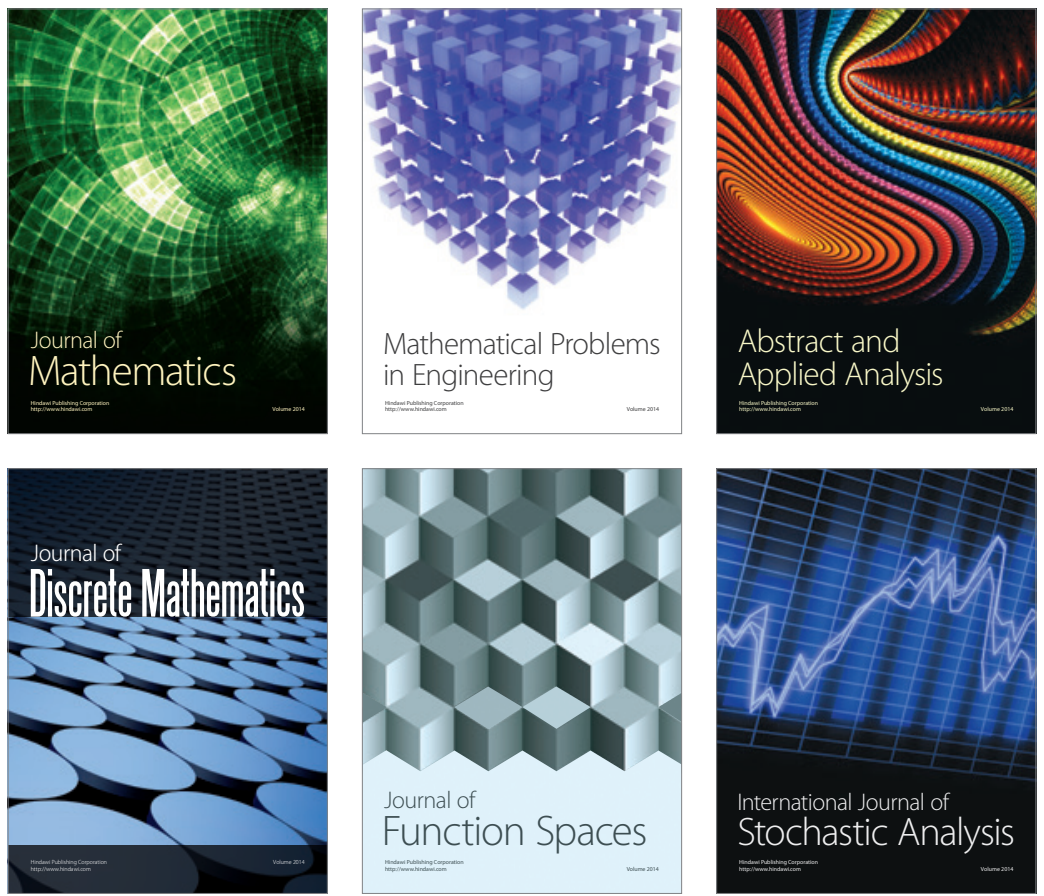

Journal of

Function Spaces

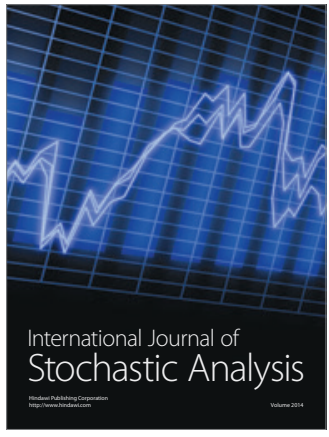

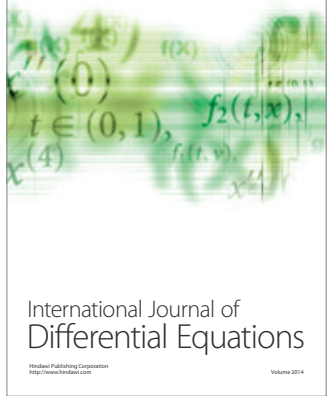
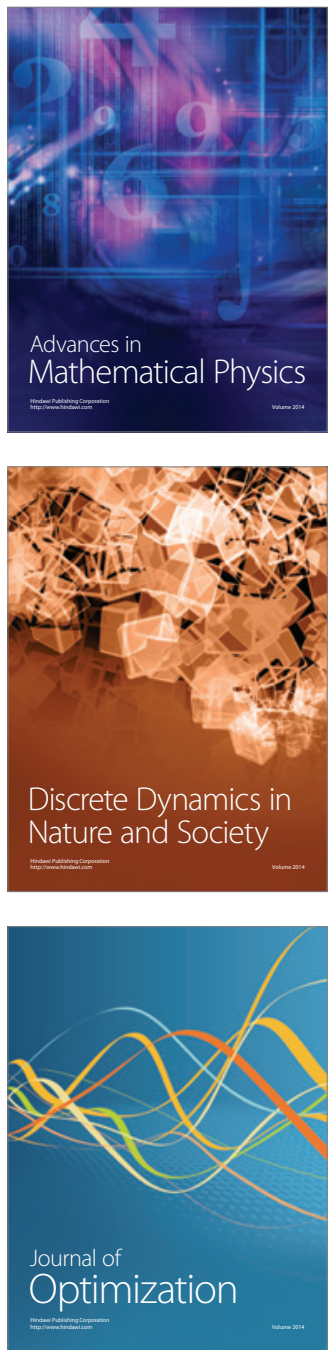